\title{
Clinical Evaluation of Javanica Oil Emulsion Injection Combined with the Radiotherapy in the Treatment of Esophageal Cancer: A Systematic Review and Meta-Analysis
}

\author{
Jiarui Wu, MD, PhD, Mengwei Ni, MM, Jialian Zhu, MS, \\ Kaihuan Wang, MM, Dan Zhang, MM, and Shuyu Liu, MM
}

\begin{abstract}
Objectives: This meta-analysis aimed to assess the clinical effectiveness and safety of Javanica oil emulsion injection (JOEI) combined with the radiotherapy (RT) for treating esophageal cancer (EC).

Design: A literature search was conducted for collecting the randomized controlled trials (RCTs) on EC treated by JOEI in the Cochrane Library, PubMed, Embase, the Chinese Biomedical Literature Database (SinoMed), the China National Knowledge Infrastructure Database, the China Science and Technology Journal Database (VIP), and the Wanfang Database from inception to February 4, 2017. The quality of the RCTs was evaluated by the Cochrane risk of bias assessment tool, and objective remission rate, performance status, adverse drug reactions (ADRs), 1-year survival rate, and 2-year survival rate were analyzed by Review Manager 5.3 and Stata 13.0 software.

Results: A total of 11 RCTs with 909 participants were involved in this meta-analysis. The results showed that in comparison with RT alone, the JOEI combined with RT was associated with the better effects on improving objective remission rate (relative risk $[R R]=1.33,95 \%$ confidence interval [CI 1.17-1.52], $Z=4.44, p<0.00001)$, performance status ( $\mathrm{RR}=1.52,95 \% \mathrm{CI}[1.25-1.85], Z=4.24, p<0.00001), 1$-year survival rate $(\mathrm{RR}=1.37,95 \% \mathrm{CI}[1.17-1.60], Z=3.86, p<0.0001)$, and 2-year survival rate $(\mathrm{RR}=1.36,95 \%$ CI [1.09-1.70], $Z=2.68, p=0.007)$. The differences between the two groups in objective remission rate, performance status, 1-year survival rate, and 2-year survival rate were statistically significant. Besides, the JOEI combined with RT could reduce the incidence of ADRs. Specifically, the statistically significant difference was detected between these two groups about leukopenia $(\mathrm{RR}=0.39,95 \%$ CI $[0.25-0.61]$, $Z=4.19, p<0.0001)$, radiation esophagitis ( $\mathrm{RR}=0.68,95 \% \mathrm{CI}[0.50-0.93], Z=2.42, p=0.02)$, thrombocytopenia $(\mathrm{RR}=0.92,95 \% \mathrm{CI}[0.12-0.66], Z=2.95, p=0.003)$, and hemoglobin reduction $(\mathrm{RR}=0.53,95 \%$ CI [0.35-0.79], $Z=3.14, p=0.002)$; however, there was no statistically significant difference for the outcome of nausea and vomiting ( $\mathrm{RR}=0.61,95 \% \mathrm{CI}$ [0.36-1.03], $Z=1.85, p=0.06$ ) between two groups.

Conclusion: This meta-analysis indicated that the combination of JOEI and RT was associated with the more beneficial treatment for patients with EC compared with only receiving RT. However, more well-designed and multicenter RCTs should be carried out to confirm this finding because of the limitations of enrolled 11 RCTs.
\end{abstract}

Keywords: Javanica oil emulsion injection, radiotherapy, esophageal cancer, randomized controlled trials, meta-analysis

Department of Clinical Chinese Pharmacy, School of Chinese Materia Medica, Beijing University of Chinese Medicine, Beijing, China.

(C) Jiarui Wu et al., 2019; Published by Mary Ann Liebert, Inc. This Open Access article is distributed under the terms of the Creative Commons License (http://creativecommons.org/licenses/by/4.0), which permits unrestricted use, distribution, and reproduction in any medium, provided the original work is properly cited. 


\section{Introduction}

$\mathbf{E}$ SOPHAGEAL CANCER (EC) IS ONE of the common alimentary system cancers worldwide. ${ }^{1,2}$ According to the relative report, its mortality may increase to 728,945 by 2035 and its incidence in men is 3-4 times higher than in females. ${ }^{3,4}$ Due to dysphagia, the patients with EC usually suffer from hiccups, weight loss, and so on in early stages. 5,6 Although the pathogeny of EC is still unclear, several chemical elements such as nitrosamines, the lack of nutrition, and some biologic factors are deemed to dangers. ${ }^{7,8}$ Currently, the treatment methods for EC were mainly radiotherapy (RT), surgery, chemotherapy, and so on. ${ }^{9}$ Among them, RT is a critical method in the treatment of EC, but adverse drug reactions (ADRs) would occur in treating, for instance, leukopenia, radiation esophagitis, nausea, and vomiting. ${ }^{10,11}$ Because of the patients' intolerance, these ADRs may cause the interruption of treatments. In recent years, the integrated treatment of EC has been gradually recognized, and Traditional Chinese Medicine (TCM) could achieve the therapeutic effects of improving clinical benefits and reducing ADRs of RT. ${ }^{12,13}$ EC belongs to dysphagia occlusion in TCM theory, which is considered as the occurrence of obstruction of esophagus caused by phlegm, blood stasis, and calculi. $^{14,15}$

As one of the most active TCM preparations against cancers, Javanica oil emulsion injection (JOEI) has been authorized by the China Food And Drug Administration to cure a wide range of solid tumors, including EC, gastrointestinal cancer, lung cancer, and ovarian cancer. ${ }^{16-20}$ It is extracted from Brucea Jen emulsion petroleum ether and purified soybean lecithin. ${ }^{21,22}$ Some previous researches indicated that the oleic acids and linoleic acids, two major active ingredients of JOEI, related with the anticancer effect by inhibiting and killing the cancer cells in the G0, G1, S, G2, and $M$ phases and DNA topoisomerases I (TOP1) or II (TOP2). ${ }^{23-25}$ Presently, there were two metaanalyses concerning about JOEI combined with RT for treating EC. ${ }^{26,27}$ Neither of them evaluate the quality of the articles and the stability of the results. Therefore, the authors performed the present meta-analysis to assess the effectiveness and safety of JOEI for EC objectively.

\section{Materials and Methods}

\section{Literature search}

The Cochrane Library, PubMed, Embase, SinoMed, China National Knowledge Infrastructure, VIP, and the Wanfang Database were systematically searched to identify randomized controlled trials (RCTs) concerning JOEI for EC from inception to February 4, 2017. The authors adopted the search strategies for each database with the combination of mesh terms and free-text terms. The manual search and gray literature search were carried out to identify the potential RCTs, including related meta-analysis, references of included RCTs, Masters' and Doctors' articles, and some ongoing research study websites.

Take the strategy of PubMed as example:

\#1 “Esophageal Neoplasms”'[Mesh]

\#2 "Esophageal Neoplasms*" [Title/Abstract] OR "Esophagus Neoplasm*"[Title/Abstract] OR "Esophagus
Cancer*"[Title/Abstract] OR "Esophageal Cancer*",[Title/Abstract] OR "Cancer of Esophagus" [Title/Abstract] \#3 \#1 OR \#2

\#4 “Javanica oil emulsion injection",[Title/Abstract] OR "Yadanzi injection"'[Title/Abstract] OR "Yandanzi'" [Title/ Abstract]OR "Brucea javanica"[Title/Abstract] \#5 \#3 AND \#4

\section{Inclusion and exclusion criteria}

RCTs were eligible if they were corresponded with the following criteria: (1) The type of articles was RCTs that focused on JOEI for EC without the restriction on the blinding method. (2) All patients were diagnosed as EC through gastrointestinal endoscopy, digestive tract endoscopy, chest computed tomography, or histopathologic diagnosis. In addition, the Karnofsky performance score (KPS) was above 60 in all patients to ensure that the longterm outcomes could be involved. The age, gender, course of disease, race, and severity of the disease were not limited. (3) Intervention for control group was RT, intensity modulated radiation therapy, three dimensional conformal radiotherapy, and conventional fractionated radiotherapy. Patients in experimental group were treated by RT plus JOEI. (4) The primary outcomes were objective remission rate and performance status. The criteria of objective remission rate abide conform to Solid Tumor Short-Term Effectiveness Criteria established by the World Health Organization. $^{28}$ Objective remission rate $=($ complete remission number + partial remission number)/total number of patients $\times 100 \%$. With regard to the improvement of performance status, it was calculated as KPS, if KPS increased 10 points were regarded as improvement of performance status. Secondary outcomes included the ADRs, survival rate, and immunologic function.

RCTs that met the following criteria were excluded: (1) Repeated published data, the full text was not available, pharmacology experiments, or individual cases. (2) TCM decoction, acupuncture, or other TCM treatments in RCTs. (3) Patients suffered from other diseases. (4) RCTs did not describe or meet the standard of efficacy. (5) RCTs were with high risk random method. (6) RCTs did not report the data of objective remission rate, performance status, and ADRs.

\section{Data extraction and quality assessment}

Data extraction was independently performed by two reviewers (J.W. and M.N.) and by utilizing NoteExpress software (Wuhan University Library, Wuhan, China) to filter the duplication and the irrelevant literatures by reading titles and abstracts. The remaining articles were browsed full text to determine whether they met the inclusion criteria or not. The following information was collected in this meta-analysis: the first author's name, publication year, number of patients, gender, age, intervention, course of treatment, and the data of outcome. The Cochrane risk of bias assessment tool was adopted for quality assessment in this meta-analysis. And it would assess the quality of RCTs from six aspects, which contained selection bias, performance bias, detection bias, attrition bias, reporting bias, and other bias with "high," "unclear," and "low" three levels. ${ }^{29}$ It was essential to 

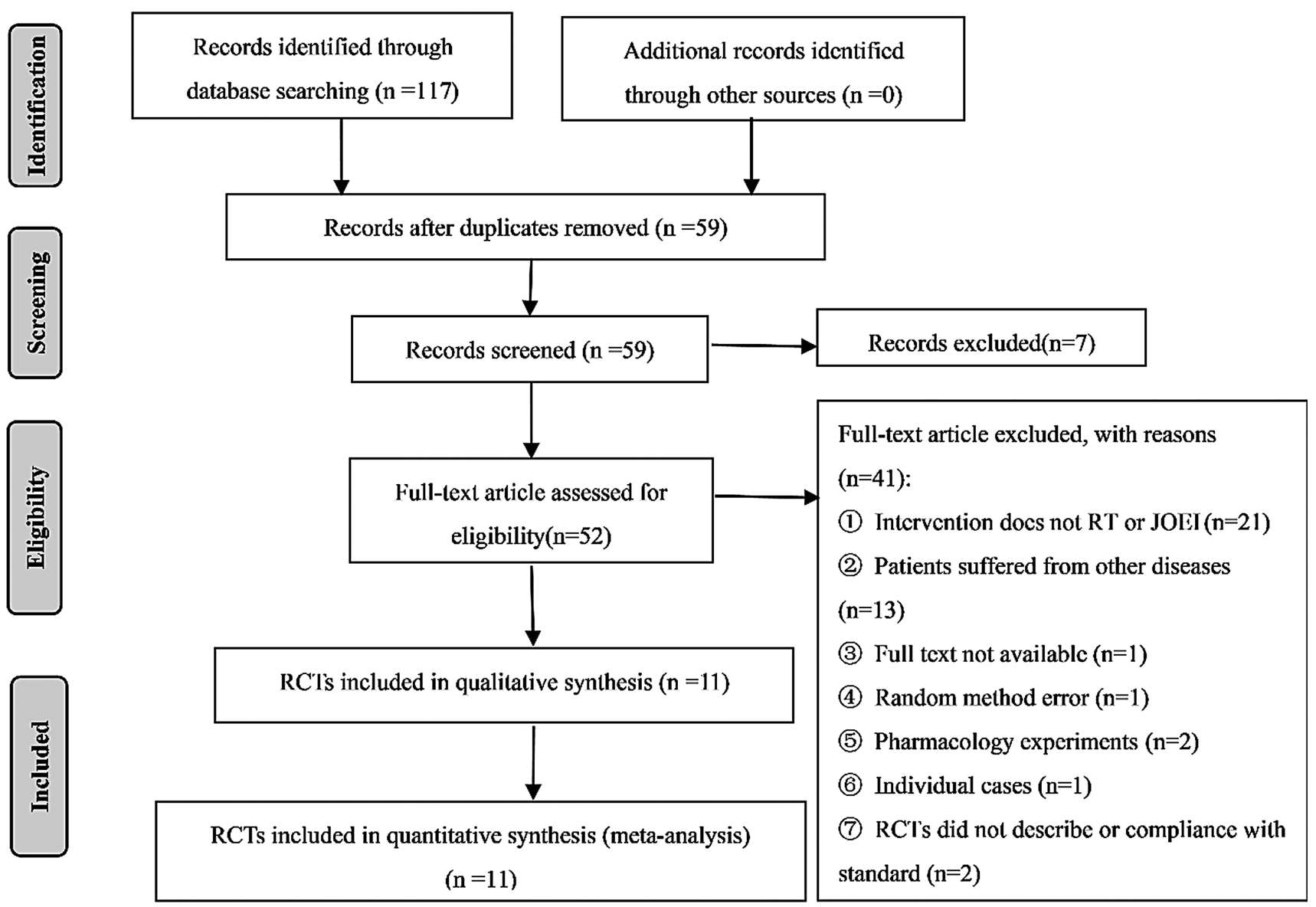

FIG. 1. Flow chart of literature search. RCTs, randomized controlled trials.

have a discussion with a third researcher (K.W.) when two reviewers emerged with different results.

Medical ethics was not obligation for this meta-analysis because the study was a systematic review of published RCTs.

\section{Statistical analysis}

Review Manager 5.3 software (Cochrane Collaboration, Oxford, United Kingdom) and Stata 13.0 software (Stata Corporation, College Station, TX) were applied to analyze the data for this meta-analysis. The relative risk (RR) was calculated for the binary variable, the mean difference was adopted for continuous variable, and each outcome was presented with 95\% confidence interval (CI). The heterogeneity among RCTs was counted by the chi-squared and $I^{2}$ tests. If $p>0.1, I^{2}<50 \%$, the fixed effect model was recommended. Otherwise, the random effect model was used. ${ }^{30}$ Subgroup analysis should be performed in consideration of clinical or methodological heterogeneity. For example, different doses or courses of interventions. Sensitivity analysis was achieved by Stata13.0

Table 1. The Basic Characteristics of the Included Randomized Controlled Trials

\begin{tabular}{|c|c|c|c|c|c|c|c|}
\hline Study ID & $\begin{array}{c}\text { Sex } \\
(M / F)\end{array}$ & $\begin{array}{l}\text { Avg. } \\
\text { age }\end{array}$ & $\begin{array}{c}\mathrm{N} \\
(E / C)\end{array}$ & Therapy of experiment & $\begin{array}{l}\text { Therapy } \\
\text { of control }\end{array}$ & $\begin{array}{c}\text { Course } \\
\text { (days) }\end{array}$ & Outcomes \\
\hline Feng $^{34}$ & $35 / 25$ & $50-81$ & $30 / 30$ & JOEI $30 \mathrm{~mL}+\mathrm{RT}$ & RT & 21 & (1) (2) \\
\hline Li et al. ${ }^{35}$ & $36 / 14$ & 62 & $25 / 25$ & JOEI $30 \mathrm{~mL}+$ IMRT & IMRT & 21 & (1) (2) (4) \\
\hline Jia et al. ${ }^{36}$ & $116 / 32$ & 55.5 & $76 / 72$ & JOEI $30-50 \mathrm{~mL}+\mathrm{RT}$ & RT & 30 & (1) (2) (3) (4) (5) \\
\hline Kong et al. ${ }^{37}$ & $47 / 13$ & 54.5 & $30 / 30$ & JOEI $30 \mathrm{~mL}+\mathrm{RT}$ & RT & 21 & (1) (2) (4) \\
\hline Liu and $\mathrm{Zhu}^{38}$ & $39 / 17$ & $30-78$ & $28 / 28$ & $\mathrm{JOEI} 30 \mathrm{~mL}+\mathrm{RT}$ & RT & 21 & (1) (2) (3) \\
\hline He et al. ${ }^{39}$ & $63 / 7$ & $52-78$ & $35 / 35$ & JOEI $30 \mathrm{~mL}+\mathrm{RT}$ & RT & $18-27$ & (1) (2) (3) \\
\hline Qi and Zhang ${ }^{40}$ & $68 / 42$ & $47-78$ & $61 / 49$ & JOEI $20-30 \mathrm{~mL}+$ TDCRT & TDCRT & 30 & (1) (2) (3) \\
\hline Sheng et al. ${ }^{41}$ & $62 / 48$ & I & $55 / 55$ & JOEI $30 \mathrm{~mL}+\mathrm{RT}$ & $\mathrm{RT}$ & 28 & (1) (2) (3) \\
\hline Jiang and Huo ${ }^{42}$ & $41 / 28$ & $39-68$ & $35 / 34$ & $\mathrm{JOEI} 30 \mathrm{~mL}+\mathrm{RT}$ & RT & $42-49$ & (1) (2) \\
\hline Li et al. ${ }^{43}$ & $37 / 19$ & $29-74$ & $28 / 28$ & JOEI $30 \mathrm{~mL}+$ TDCRT & TDCRT & 21 & (1) (2) (4) \\
\hline Liu and $\mathrm{Zuo}^{44}$ & $87 / 33$ & $40-83$ & $60 / 60$ & JOEI $30 \mathrm{~mL}+$ CFRT & CFRT & 21 & (1) (2) (4) \\
\hline
\end{tabular}

(1), objective remission rate; (2), ADR; (3), life status improvement rate; (4), survival rate; (5), immunologic function.

$\mathrm{ADR}$, adverse drug reaction; C, control group; CFRT, conventional fractionated radiotherapy; E, experiment group; F, female; IMRT, intensity modulated radiation therapy; JOEI, Javanica oil emulsion injection; M, male; RT, radiotherapy; TDCRT, three dimensional conformal radiotherapy. 


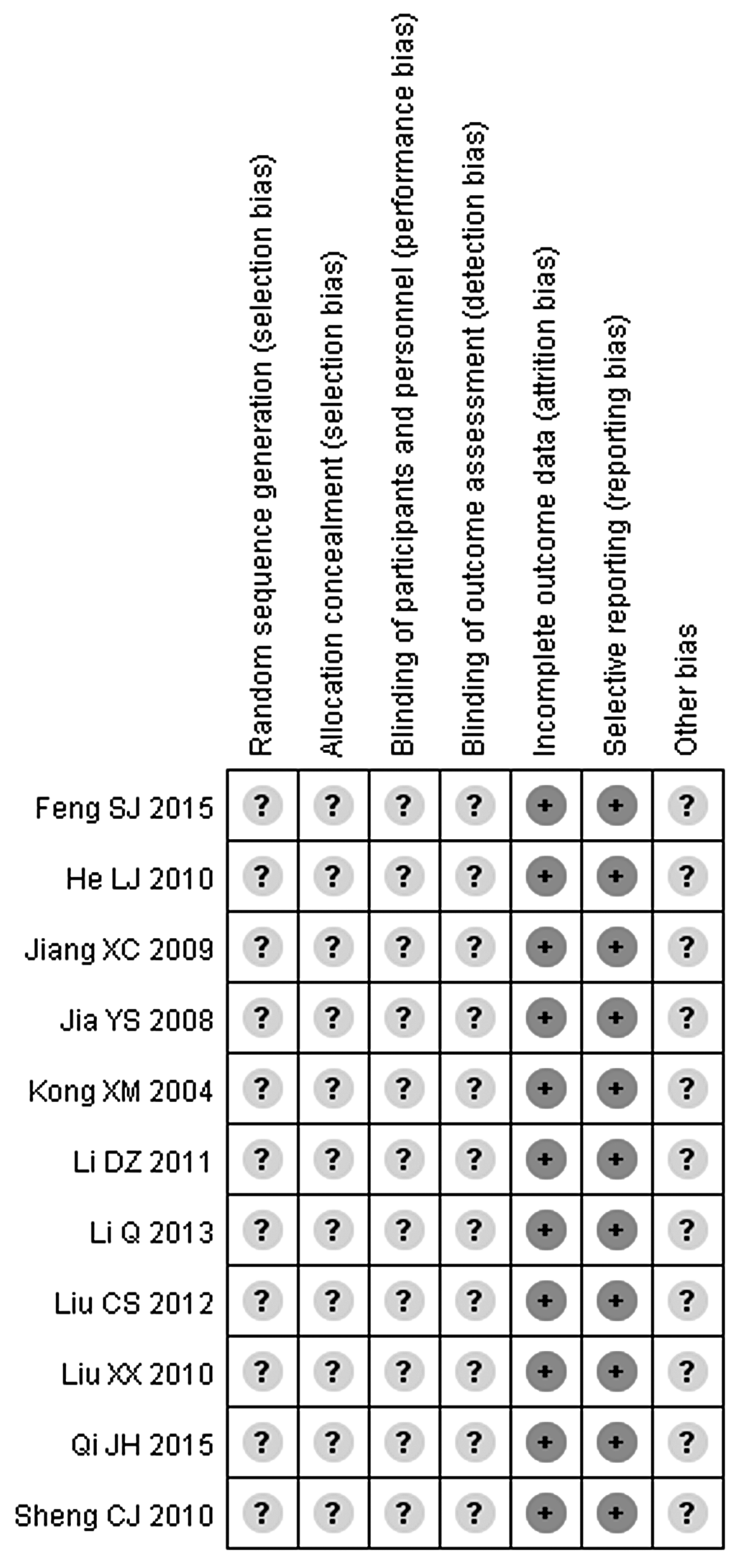

FIG. 2. Risk of bias graph. Low risk is indicated with a question mark, and unclear bias is indicated with a plus sign. software to evaluate the stability of the results. ${ }^{31}$ In addition, the Funnel plot, Begg's, and Egger's tests were administered to detect publication bias. In Begg's and Egger's tests, $p<0.05$ indicated a certain publication bias among included RCTs. ${ }^{32}$

\section{Results}

\section{Study characteristics}

Initially, 117 potentially relevant articles were retrieved, after screening titles and abstracts to exclude duplication and irrelevant articles; 52 articles remained for full-text review. Furthermore, 41 articles were ruled out for reasons described in Figure 1, and 11 RCTs were eligible in this meta-analysis ultimately. The 11 RCTs enrolled 909 patients, in which 463 cases were in the experimental group and 446 cases were in the control group. The age range of patients was from 30 to 81 years old. Among them, male patients accounted for $69.42 \%$. The majority dosage of JOEI was $30 \mathrm{~mL} /$ day, and the course of treatment was more than 18 days (Table 1).

As Figure 2 presented, the Cochrane risk of bias assessment tool was applied to evaluate the quality of the RCTs. None of them mentioned the specific grouping method, the concealment of random sequences, and the implementation of blinding, so the selective bias, the performance bias, and the detection bias were judged as "unclear." Moreover, because of the inexistence of selective reporting and case detachment in all RCTs, their attrition bias and reporting bias were assessed as "low risk." Owning to the RCTs did not describe the bias of other aspects; the others bias was remarked as "unclear."

\section{Outcomes}

Objective remission rate. A total of six RCTs described the statistics of objective remission rate. ${ }^{33,36,38-41}$ Small heterogeneity was detected among them $\left(p=0.24>0.1, I^{2}=26 \%\right.$ $<50 \%$ ), so the fixed effect model was used. As displayed in Figure 3, the result of meta-analysis manifested that compared with RT, JOEI plus RT could increase the objective remission rate to about $23 \%$. The difference between the two groups was statistically significant $(\mathrm{RR}=1.33,95 \%$ CI $[1.17-$ 1.52], $Z=4.44, p<0.00001)$.

Performance status. Four RCTs listed the details about performance status. ${ }^{35,37,39,40}$ Heterogeneity was moderate among the RCTs $\left(p=0.58>0.1, I^{2}=0 \%<50 \%\right)$; hence a fixed

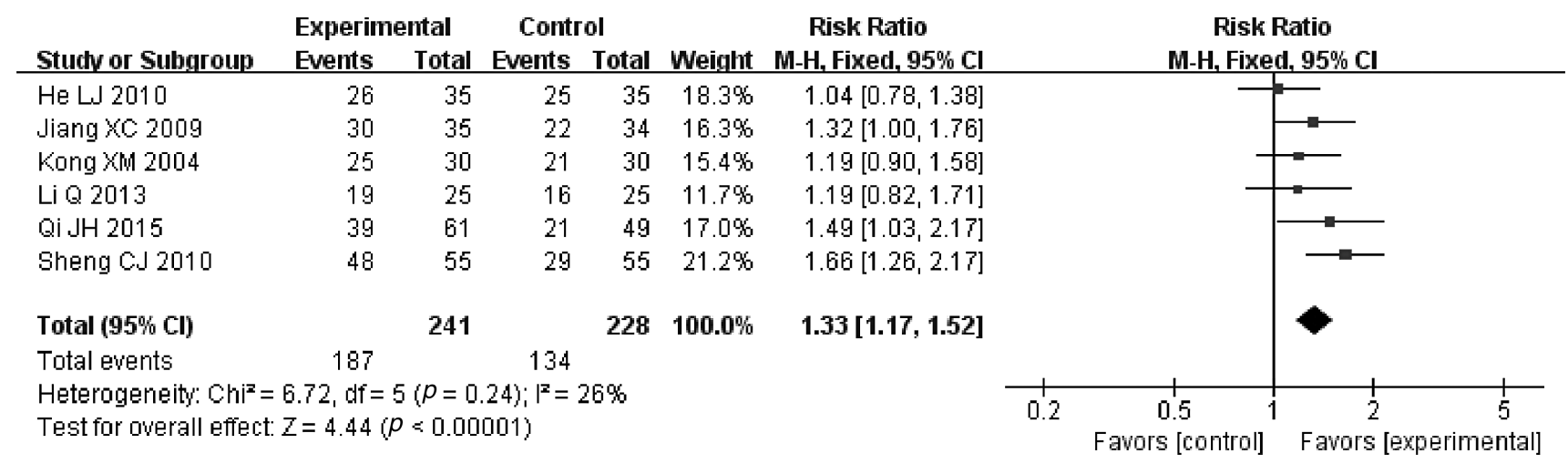

FIG. 3. Meta-analysis in objective remission rate between JOEI + RT and RT. CI, confidence interval; JOEI, Javanica oil emulsion injection; RT, radiotherapy. 


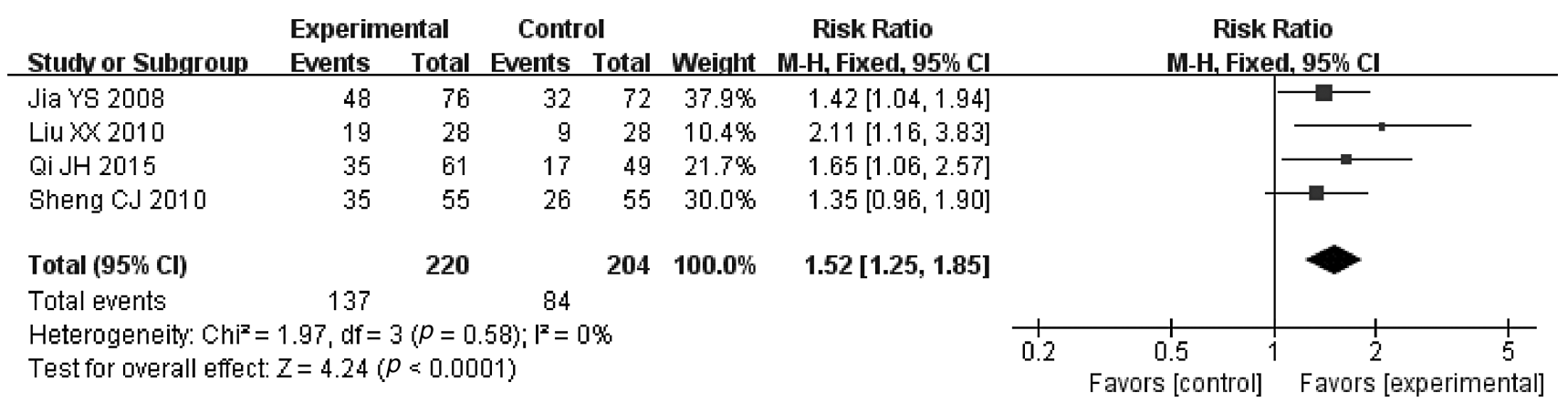

FIG. 4. Meta-analysis in Performance Status Improvement Rate between JOEI+RT and RT. CI, confidence interval; JOEI, Javanica oil emulsion injection; RT, radiotherapy.

effect model was chosen. The result of meta-analysis showed that compared with only undergoing RT treatment, JOEI associated with RT can enhance the performance status of patients with EC to about $59 \%$. In addition, there was a statistically significant difference between the two groups $(\mathrm{RR}=1.52,95 \% \mathrm{CI}[1.25-1.85], Z=4.24, p<0.00001)$ (Fig. 4).

Adverse drug reactions. All RCTs in this meta-analysis recorded the ADRs; their study mainly covered the leukopenia, radiation esophagitis, thrombocytopenia, hemoglobin reduction, nausea, and vomiting.

Leukopenia. Five RCTs recorded the leukopenia. ${ }^{34,36-38,41}$ The heterogeneity was small $\left(p=0.69>0.1, I^{2}=0 \%<50 \%\right)$; thus, the fixed effect model was implemented. Meta-analysis revealed that compared with the control group only using RT,
JOEI with RT can reduce leukopenia. Besides, the statistically significant difference was detected between these two groups $(\mathrm{RR}=0.39,95 \% \mathrm{CI}[0.25-0.61], Z=4.19, p<0.0001)$ (Fig. 5A).

Radiation esophagitis. Six RCTs noted information about the radiation esophagitis. ${ }^{35-38,41,43}$ Heterogeneity was high among the RCTs $\left(p=0.0005>0.1, I^{2}=70 \%>50 \%\right)$; therefore, the random effect model was used. The result of metaanalysis indicated that compared with RT alone, JOEI combined with $\mathrm{RT}$ can reduce radiation esophagitis in EC patients, and the difference between the two groups was statistically significant $(\mathrm{RR}=0.68,95 \%$ CI [0.50-0.93], $Z=2.42, p=0.02)$ (Fig. 5B).

As displayed in Table 2, other ADRs mainly included thrombocytopenia, ${ }^{34,37}$ hemoglobin reduction, ${ }^{34,37}$ nausea,

\begin{tabular}{|c|c|c|c|c|c|c|c|c|}
\hline $\begin{array}{l}\text { A } \\
\text { Studv or Subgroup }\end{array}$ & $\begin{array}{l}\text { Experim } \\
\text { Events }\end{array}$ & $\begin{array}{l}\text { ental } \\
\text { Total }\end{array}$ & $\begin{array}{c}\text { Contr } \\
\text { Events }\end{array}$ & Total & Weight & $\begin{array}{c}\text { Risk Ratio } \\
\text { M-H, Fixed, 95\% Cl }\end{array}$ & $\begin{array}{r}\text { Risk R } \\
\text { M-H, Fixed }\end{array}$ & $\begin{array}{l}\text { Ratio } \\
\text { d, } 95 \% \mathrm{Cl}\end{array}$ \\
\hline Feng SJ 2015 & 4 & 30 & 11 & 30 & $19.6 \%$ & $0.36[0.13,1.01]$ & & \\
\hline He LJ 2010 & 7 & 35 & 12 & 35 & $21.4 \%$ & $0.58[0.26,1.31]$ & & \\
\hline Jiang $X C 2009$ & 3 & 35 & 5 & 34 & $9.0 \%$ & $0.58[0.15,2.25]$ & & \\
\hline Kong XM 2004 & 5 & 30 & 15 & 30 & $26.8 \%$ & $0.33[0.14,0.80]$ & & \\
\hline Liu $\times \propto 2010$ & 3 & 28 & 13 & 28 & $23.2 \%$ & $0.23[0.07,0.72]$ & & \\
\hline Total $(95 \% \mathrm{Cl})$ & & 158 & & 157 & $100.0 \%$ & $0.39[0.25,0.61]$ & & \\
\hline Total events & 22 & & 56 & & & & & \\
\hline $\begin{array}{l}\text { Heterogeneity: } \text { Chi }^{2}= \\
\text { Test for overall effect }\end{array}$ & $\begin{array}{l}2.25, \mathrm{df}= \\
Z=4.19\end{array}$ & $\begin{array}{l}4 p=0 \\
<0.00\end{array}$ & 69); $1^{2}=0$ & & & & $\begin{array}{ccc}0.02 & 0.1 & 1 \\
\text { Favors [experimental] }\end{array}$ & Favors [control] \\
\hline B & $\begin{array}{l}\text { Experim } \\
\text { Events }\end{array}$ & $\begin{array}{l}\text { ntal } \\
\text { Total } \\
\end{array}$ & $\begin{array}{l}\text { Contro } \\
\text { Events } \\
\end{array}$ & Total & Weight & $\begin{array}{c}\text { Risk Ratio } \\
\text { M-H, Random, } 95 \% \mathrm{Cl}\end{array}$ & $\begin{array}{r}\text { Risk } \\
\text { M-H, Rando } \\
\end{array}$ & $\begin{array}{l}\text { Ratio } \\
\text { om, } 95 \% \mathrm{Cl}\end{array}$ \\
\hline He LJ 2010 & 14 & 35 & 18 & 35 & $15.8 \%$ & $0.78[0.46,1.31]$ & & \\
\hline Jia YS 2008 & 35 & 76 & 45 & 72 & $22.2 \%$ & $0.74[0.54,1.00]$ & & \\
\hline Jiang XC 2009 & 30 & 35 & 31 & 34 & $25.9 \%$ & $0.94[0.79,1.12]$ & & \\
\hline Kong XM 2004 & 4 & 30 & 11 & 30 & $6.9 \%$ & $0.36[0.13,1.01]$ & & \\
\hline Liu CS 2012 & 21 & 60 & 34 & 60 & $18.9 \%$ & $0.62[0.41,0.93]$ & & \\
\hline Liu $\nsim 2010$ & 6 & 28 & 16 & 28 & $10.2 \%$ & $0.38[0.17,0.82]$ & & \\
\hline Total $(95 \% \mathrm{Cl})$ & & 264 & & 259 & $100.0 \%$ & $0.68[0.50,0.93]$ & & \\
\hline Total events & 110 & & 155 & & & & & \\
\hline \multicolumn{8}{|c|}{$\begin{array}{l}\text { Heterogeneity: } \text { Tau }^{2}=0.09 ; \mathrm{Chi}^{2}=16.75, \mathrm{df}=5(p=0.005) ;\left.\right|^{2}=70 \% \\
\text { Test for overall effect: } Z=2.42(p=0.02)\end{array}$} & $\begin{array}{cccc} & 1 & 5 & 10 \\
\text { Favors [control] }\end{array}$ \\
\hline
\end{tabular}

FIG. 5. Meta-analysis in adverse drug reactions in between JOEI + RT and RT. (A) Leukopenia, (B) radiation esophagitis. CI, confidence interval; JOEI, Javanica oil emulsion injection; RT, radiotherapy. 
Table 2. Meta-Analysis of Other Adverse Drug Reactions

\begin{tabular}{lccccc}
\hline Outcomes & Number of RCTs & Model & RR [95\% CI] & $\mathrm{Z}$ & $\mathrm{p}$ \\
\hline Thrombocytopenia & 2 & Fixed effect & $0.92[0.12-0.66]$ & 2.95 & 0.003 \\
Hemoglobin reduction & 2 & Fixed effect & $0.53[0.35-0.79]$ & 3.14 & 0.002 \\
Nausea and vomiting & 3 & Fixed effect & $0.61[0.36-1.03]$ & 1.85 & 0.06 \\
\hline
\end{tabular}

$\mathrm{CI}$, confidence interval; RCT, randomized controlled trial; RR, relative risk.

and vomiting. ${ }^{34,36,38}$ Compared with RT alone, the combination of RT and JOEI had a better effect on relieving thrombocytopenia and hemoglobin reduction; the difference was statistically significant between two groups $(p<0.05)$. However, there was no statistically significant difference for the outcome of nausea and vomiting between two groups $(p>0.05)$.

\section{Survival rate}

One-year survival rate. One-year survival rate had appeared in four RCTs. ${ }^{35,36,42,43}$ The heterogeneity test $\left(p=0.98>0.1, I^{2}=0 \%<50 \%\right)$ texted the existence of small heterogeneity; thus, the fixed effect model was applied. Meta-analysis signified that there was significant difference between the two groups in this outcome. The 1-year survival rate in JOEI combined with RT group was associated with a higher 1-year survival rate $(\mathrm{RR}=1.37,95 \% \mathrm{CI}$ [1.17-1.60], $Z=3.86, p<0.0001$ ) (Fig. 6A).
Two-year survival rate. Four RCTs reported the 2-year survival rate. ${ }^{35,36,42,43}$ The heterogeneity test $(p=0.40>0.1$, $I^{2}=0 \%<50 \%$ ) measured the heterogeneity which was small, thus the fixed effect model was performed. Meta-analysis discovered that JOEI cooperated with RT was associated with a higher 2-year survival rate. Moreover, difference between groups was statistically significant $(\mathrm{RR}=1.36,95 \%$ CI [1.09-1.70], $Z=2.68, p=0.007$ ) (Fig. 6B).

\section{Immunologic function}

There was only one $\mathrm{RCT}^{35}$ that recorded the $\mathrm{T}$ lymphocyte subsets comparing the two groups; thus, the metaanalysis performed a qualitative description for this outcome. The specific results are shown in Table 3.

\section{Sensitivity analysis}

Sensitivity analysis was conducted for objective remission rate. As shown in Figure $7 \mathrm{~A}$, the results were not

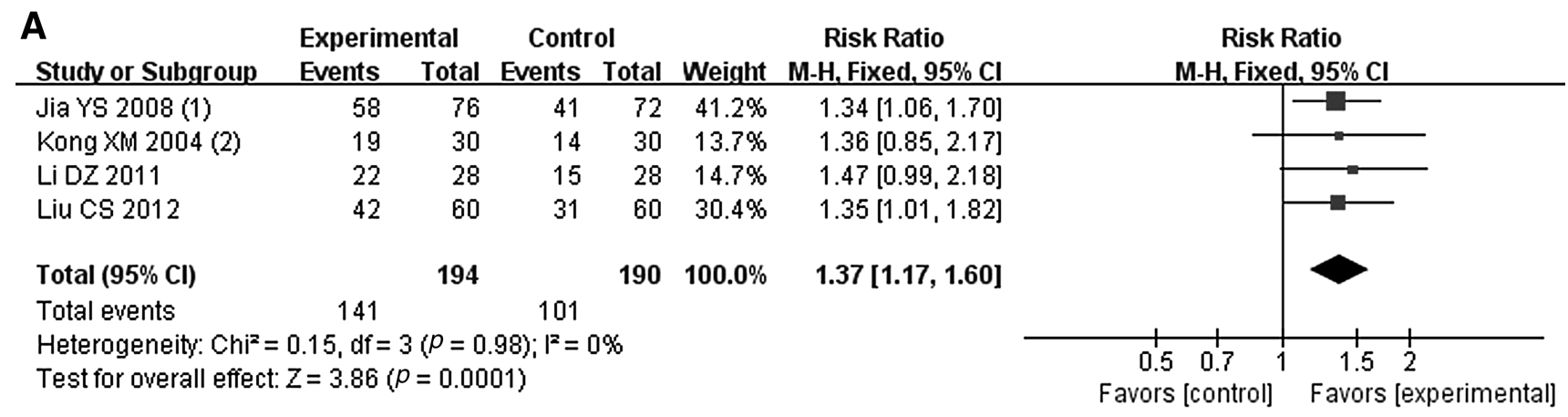

(1) Experimental group lost to follow-up one case, control group lost to follow-up two cases

(2) Experimental group lost to follow-up two cases, control group lost to follow-up one case

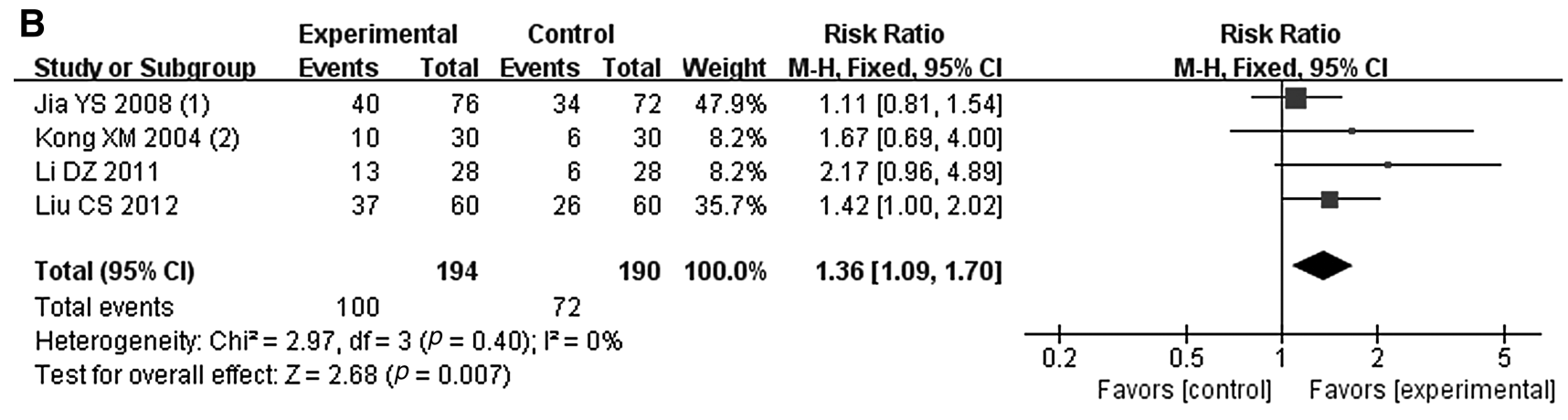

(1) Experimental group lost to follow-up one case, control group lost to follow-up two cases

(2) Experimental group lost to follow-up two cases, control group lost to follow-up one case

FIG. 6. Meta-analysis in survival rate between JOEI + RT and RT. (A) One-year survival rate, (B) 2-year survival rate. CI, confidence interval; JOEI, Javanica oil emulsion injection; RT, radiotherapy. 
Table 3. Meta-Analysis of Immunologic Function

\begin{tabular}{lrrrrrrr}
\hline & \multicolumn{2}{c}{$E$} & & \multicolumn{2}{c}{$C$} & \\
\cline { 2 - 3 } Outcomes & $\begin{array}{l}\text { Mean } \\
\text { value }\end{array}$ & $\begin{array}{l}\text { Standard } \\
\text { deviation }\end{array}$ & $\begin{array}{l}\text { Mean } \\
\text { value }\end{array}$ & $\begin{array}{c}\text { Standard } \\
\text { deviation }\end{array}$ & $\mathrm{p}$ \\
\hline $\mathrm{CD}^{+} / \%$ & 53.16 & 4.82 & & 50.20 & 8.41 & $<0.05$ \\
$\mathrm{CD} 4^{+} / \%$ & 32.21 & 5.73 & & 26.10 & 5.13 & $<0.05$ \\
$\mathrm{CD}^{+} / \%$ & 24.10 & 3.16 & & 27.98 & 4.42 & $<0.05$ \\
$\mathrm{CD}^{+} / \mathrm{CD}^{+}$ & 1.38 & 0.34 & & 1.06 & 0.29 & $<0.05$
\end{tabular}

E, experiment group; C, control group.

changed by combining effect, indicating that the results of this meta-analysis were steady.

\section{Evaluation of publication bias}

The results of the Begg's test $(p=0.707>0.05)$ and Egger's test $(p=0.922>0.05)$ demonstrated that there were no obvious publication biases among included RCTs, and the distribution of RCTs was relatively symmetrical as well, as shown in Figure $7 \mathrm{~B}$.

\section{Discussion}

In the present meta-analysis, the authors discussed the clinical effectiveness and safety of JOEI for treating EC. The results illustrated that the combination of JOEI based on RT had a better therapeutic effect for patients with EC. It can be reflected in the following aspects: JOEI combined with RT can not only ameliorate objective remission rate, performance status, 1-year survival rate, and 2-year survival rate but also relieve the ADRs caused by RT such as leukopenia, radiation esophagitis, thrombocytopenia, and hemoglobin reduction.

As ranking sixth among cancer worldwide, EC can appear in any part of the tube, and more than 450,000 cases are diagnosed with EC per year. ${ }^{44,45}$ Because of the atypical symptoms at earlier stages, it is always diagnosed at later stages. ${ }^{46-48}$ Besides, dysphagia is the most common symptom for patients with advanced EC. ${ }^{49}$ Owing to its complication, poor general conditions, and advanced age, the therapy of surgery or chemotherapy is often limited. Moreover, the 5- year overall survival rate for patients with EC is only $0 \%-$ $20 \%$, which is still poor after RT treatment alone. ${ }^{50-53} \mathrm{RT}$ combined with TCM can not only improve the sensitivity of tumor cells to radiation but also reduce the ADRs of RT. ${ }^{54}$

Bencao Gangmu Shiyi recorded that Brucea Jen emulsion medicine in taste is bitter and in properties is cold. It has the effect of clearing heat to dry, killing parasites, and removing toxic substances. ${ }^{55-57}$ The mechanism of the JOEI may inhibit the activity of topoisomerase, blocking the proliferation of cancer cells, killing and impeding the cancer cells. ${ }^{58}$ JOEI could lead cancer cell death by both caspase- 3 and caspase- 9 or inhibition of NF-kappa B and Cyclooxygenase-2. ${ }^{59} \mathrm{JOEI}$ is remarkable of its antitumor activity, and other pharmacologic experiment noted that JOEI can inhibit the proliferation of cancer cells by inhibiting the DNA synthesis. ${ }^{60-63}$

There were three prior meta-analyses ${ }^{26,27,64}$ on the treatment of EC with the application of JOEI, which contained two traditional meta-analyses. ${ }^{26,27}$ Among them, one was published in 2015, and two were published in 2016. In comparison, their meta-analysis has following advantages: First, this metaanalysis renewed the literature retrieval time and applied the search strategy of combining keywords and free-text words for a more comprehensive retrieval; for instance, two of RCTs included in this meta-analysis were published after 2015, while the lasted times for RCTs in the two prior meta-analyses were in 2013. Second, in this meta-analysis, all RCTs strictly conformed to inclusion and exclusion criteria to ensure the consistency of the baseline and reduce the clinical heterogeneity. Third, Stata 13.0 and RevMan 5.3 software were applied to analyze data, as well as examine the stability of the results through sensitivity analysis. Finally, outcomes of this meta-analysis not only concerned the objective remission rate and performance status but also the ADRs, which can effectively respond to the effectiveness of treatment for the patients with EC.

\section{Limitations}

This meta-analysis also has a few limitations. First, the quality of the 11 RCTs enrolled in their study was not high. RCTs were all in Chinese and did not refer to the specific random grouping method; meanwhile the blind method and the covert grouping were not applied as well. Second, RCTs
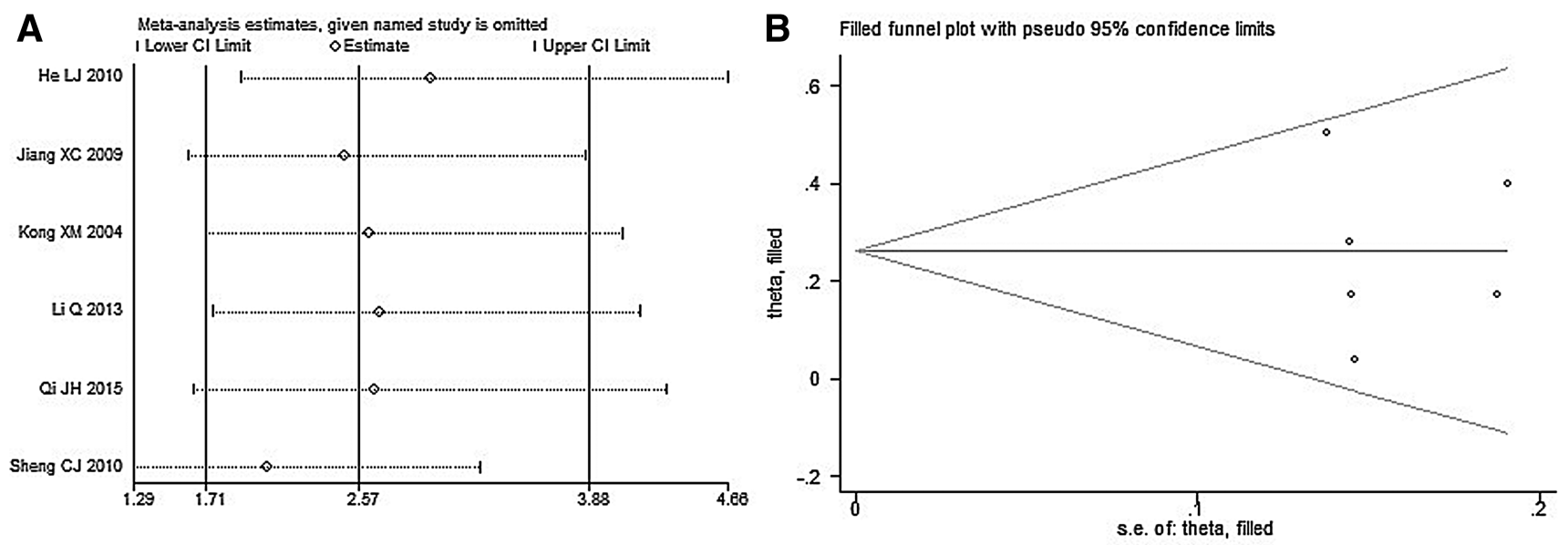

FIG. 7. Sensitivity analysis and Funnel plot of objective remission rate. (A) Sensitivity analysis of objective remission rate, (B) Funnel plot of objective remission rate. 
were mainly distributed at the bottom of the funnel, indicating a lack of a large sample of RCTs, which may increase the impact of treatment. Third, the survival rate is an important indicator for tumor treatment; however, because of the small number of included RCTs that mentioned survival rate the authors regarded it as a secondary outcome and RCTs also lacking of long-term outcomes, such as 3-year survival rate, follow-up data, and so on.

To provide the high-quality evidence, their study suggested that RCTs should pay more attention to long-term outcomes like survival rate. Furthermore, the quality of the RCTs should be improved, and clinician ought to emphasize the random methods, concealment of random sequence, implementation of blinding, and so on.

\section{Conclusions}

In summary, the results of this meta-analysis illustrated that JOEI combined with RT had a better clinical effectiveness for EC. Nevertheless, the results of this metaanalysis need to be further validated by multicenter and larger sample RCTs (Supplementary Table S1).

\section{Acknowledgment}

This article was supported by the National Nature Science Foundation of China (No. 81473547; No. 81673829).

\section{Author's Contributions}

Conceptualization: J.W. and M.N. Data curation: J.W., M.N., J.Z., K.W., D.Z., and S.L. Formal analysis: J.W. and M.N. Investigation: J.W., M.N., J.Z., K.W., D.Z., and S.L. Methodology: J.W., D.Z., M.N., and K.W. Project administration: J.W. Software: J.W., D.Z., and K.W. Writing-original draft: J.W. and M.N. Writing-review and editing: J.W.

\section{Author Disclosure Statement}

No competing financial interests exist.

\section{Supplementary Material}

Supplementary Table S1

\section{References}

1. Alema ON, Iva B. Cancer of the esophagus: Histopathological sub-types in northern Uganda. Afr Health Sci 2014; 14:17-21.

2. Zeng L, Zhou HY, Tang NN, et al. Wortmannin influences hypoxia-inducible factor-1 alpha expression and glycolysis in esophageal carcinoma cells. World J Gastroenterol 2016; 22:4868-4880.

3. Ervik M, Lam F, Ferlay J, et al. Cancer today [homepage on the Internet]. Lyon, France: International Agency for Research on Cancer. Cancer Today, 2016. Online document at: http://gco.iarc.fr/today, accessed November 22, 2017.

4. Volpin E, Sauvanet A, Couvelard A, Belghiti J. Primary malignant melanoma of the esophagus: A case report and review of the literature. Dis Esophagus 2002;15:244-249.

5. Ojala K, Sorri M, Jokinen K, Kairaluoma M. Symptoms of carcinoma of the oesophagus. Med J Aust 1982;1:384-385.

6. Sabanathan S, Eng J. Primary malignant melanoma of the esophagus. Scand J Thorac Cardiovasc Surg 1990;24:83-85.

7. Wu Y, He YT. Etiology of esophageal cancer. J Esophageal Surg (Electronic Version) 2014;2:114-120.
8. Zhang TB, Hou PG. Research progress on etiology of esophageal cancer. Sichuan J Anat 2015;23:28-30.

9. Liang J, E M, Wu G, et al. Nimotuzumab combined with radiotherapy for esophageal cancer: Preliminary study of a phase II clinical trial. Onco Targets Ther 2013; 6:1589-1596.

10. Kole TP, Aghayere O, Kwah J, et al. Comparison of heart and coronary artery doses associated with intensity-modulated radiotherapy versus three-dimensional conformal radiotherapy for distal esophageal cancer. Int J Radiat Oncol Biol Phys 2012;83:1580-1586.

11. Wang D, Yang Y, Zhu J, et al. 3D-conformal RT, fixed-field IMRT and rapid arc, which one is better for esophageal carcinoma treated with elective nodal irradiation. Technol Cancer Res Treat 2011;10:487-494.

12. Huang $\mathrm{H}, \mathrm{Xu} \mathrm{PF}$, Wei PF. A meta-analysis of survival of middle and late stage esophageal carcinoma treated with radiotherapy combined with traditional Chinese medicine. J Mod Oncol 2017;25:1413-1417.

13. Lin L, Cao P. Advances in clinical research of radiotherapy and chemotherapy combined with Chinese medicine treatment for esophageal cancer. World Chin J Digesto 2012;35: 3505-3509.

14. Chen J. Theoretical study of TCM syndrome before and after radiotherapy of esophageal cancer. World Latest Medicine Inf 2017;54:92.

15. Liu J, Li LP, Zhao YG. Research progress of TCM syndrome types and treatment of esophageal cancer. Chin Arch Tradit Chin Med 2017;7:1772-1774.

16. Gao H, Lamusta J, Zhang WF, et al. Tumor cell selective cytotoxicity and apoptosis Induction by an herbal preparation from Brucea javanica. N Am J Med Sci (Boston) 2011;4:62-66.

17. Zhang D, Wu JR, Zhang B, Liu S. Meta-analysis of Javanica oil emulsion injection plus transcatheter hepatic arterial chemoembolizationin treatment with liver carcinoma. Chin J Pharmacoepidemiol 2017;26:171-176.

18. Lau FY, Chui CH, Gambari R, et al. Antiproliferative and apoptosis-inducing activity of Brucea javanica extract on human carcinoma cells. Int J Mol Med 2005;16:1157-1162.

19. Ma YK, Hu AX, Zou M. Progress in clinical application of Brucea javanica oil. Shandong Med J 2004;44:61-62.

20. Wang Q, Wang MC, He RX, et al. Meta-analysis of Brucea javanica oil emulsion combined with platinum based firstline chemotherapy in the treatment of non-small cell lung cancer. China J Chin Mater Med 2012;37:2022-2029.

21. Liu J, Huang XE, Tian GY, et al. Phase II study on safety and efficacy of Yadanzi(R) (Javanica oil emulsion injection) combined with chemotherapy for patients with gastric cancer. Asian Pac J Cancer Prev 2013;14:2009-2012.

22. Lu YY, Huang XE, Cao J, et al. Phase II study on Javanica oil emulsion injection (Yadanzi(R)) combined with chemotherapy in treating patients with advanced lung adenocarcinoma. Asian Pac J Cancer Prev 2013;14:4791-4794.

23. Jin W, Han H, Zhou S, et al. Therapeutic efficacy of Brucea javanica oil emulsion (BJOEI) combined with transcatheter hepatic arterial chemoembolization (TACE) in patients with primary liver cancer. Int J Clin Exp Med 2015;8: 18954-18962.

24. Zhang H, Yang JY, Zhou F, et al. Seed oil of Brucea javanica induces apoptotic death of acute myeloid leukemia cells via both the death receptors and the mitochondrialrelated pathways. Evid Based Complement Alternat Med 2011;2011:965016. 
25. Han F, Cai D, Wu X, Zhai X. Research progress of Brucea javanica antitumor mechanism. J Mod Oncol 2013;212: 669-671.

26. Chen J, Li LL, Zhang DR, et al. Meta-analysis of javanica oil emulsion injection combined with radiotherapy in the treatment of esophageal carcinoma. J Pract Med 2015;31: 2182-2185.

27. Yang Z, Li Y, Wan XY, et al. Effectiveness and safety of oleum fructus bruceae combined with radiotherapy treatment of esophageal cancinoma: A meta-analysis. Chongqing Med 2016;45:1937-1941.

28. Staquet M. Reporting results of cancer treatment. Cancer 1981;47:207-214.

29. Higgins JPT, Altman DG, Gøtzsche PC, et al. The Cochrane Collaboration's tool for assessing risk of bias in randomised trials. BMJ 2011;343:889-893.

30. Zheng MH. Applications and Example Analyzation of the Meta-Analysis Software. People's Medical Publishing House, Beijing, China: 2013.

31. O'Rourke K, Shea B, Wells GA. Meta-Analysis of Clinical Trials. New York: Springer, 2001.

32. Egger M, Davey Smith G, Schneider M, et al. Bias in metaanalysis detected by a simple, graphical test. BMJ 1997; 315:629-634.

33. Li Q, Deng SH, Chen T. The observation of intensitymodulated radiotherapy combined with Brucea javanica oil emulsion in treatment of recurrent esophageal cancer. Shanxi Med J 2013;42:86-87.

34. Feng SJ. Study on the clinical curative effect of Brucea javanica oil injection combined with radiotherapy for patients with esophageal cancer. China Heal Care Nutr 2015;12:130-131.

35. Jia YS, Wu SQ, Lv SL, et al. Clinical analysis of radiotherapy combined with Brucea javanica oil in the treatment of advanced esophageal cancer. China J Chin Mater Med 2008;33:2174-2176.

36. Kong XM, Xu LJ, Zhang N, Liu SY. Clinical observation on treating advanced esophageal cancer with emulsion injection of seminal oil plus radiotherapy. Zhejiang J Integr Tradit Chin Western Med 2004;14: 339-340.

37. Liu XX, Zhu H. 28 cases of esophageal cancer treatment of Brucea javanica oil injection combined with radiotherapy. Jiangxi J Tradit Chin Med 2010;41:42-43.

38. He LJ, Luo HQ, Xiang L. Efficacy of Brucea javanica oil emulsion combined radiotherapy on treating advanced esophageal carcinoma. Chin J Exp Tradit Med Formulae 2010;16:212-214.

39. Qi JH, Zhang LZ. Brucea javanica oil injection combined with conformal radiotherapy to observe the curative effect in the treatment of locally advanced esophageal carcinoma. Henan Med Res 2015;24:60-62.

40. Sheng ZJ, Sun J, Feng LJ. Observation of curative effect of Brucea javanica oil injection combined with radiotherapy in the treatment of elderly patients with advanced esophageal cancer. China Heal Care Nutr 2010;6:185-186.

41. Jiang XC, Huo SX. Clinical study of yadanzi oil emulsion injection ireproving efficocy on radiotherapy in treatment of esophageal cancer. World Heal Dig Med Periodieal 2009;6:35-36.

42. Li DZ, Li GM, Wen SM. Three dimensional conformal radiotherapy combined with Brucea javanica oil emulsion injection in the treatment of 28 patients with recurrent esophageal carcinoma after radiotherapy. Chongqing Med 2011;40:170-171.

43. Liu CS, Zuo L. Brucea javanica oil with short-term efficacy of radiotherapy for esophageal carcinoma. Chin J Misdiagn 2012;12:4937-4938.

44. Ferlay J, Soerjomataram I, Dikshit R, et al. Cancer incidence and mortality worldwide: Sources, methods and major patterns in GLOBOCAN 2012. Int J Cancer 2015; 136:E359.

45. Pennathur A, Gibson MK, Jobe BA, et al. Oesophageal carcinoma. Lancet 2013;381:400-412.

46. Ferlay J, Shin HR, Bray F, et al. Estimates of worldwide burden of cancer in 2008: GLOBOCAN 2008. Int J Cancer 2010;127:2893-2917.

47. Saeid G, Ardekani AM. Non-invasive detection of esophageal cancer using genetic changes in circulating cell-free DNA. Avicenna J Med Biotechnol 2012;4:3-13.

48. Xu D, Li G, Li H, Jia F. Comparison of IMRT versus 3DCRT in the treatment of esophagus cancer: A systematic review and meta-analysis. Medicine (Baltimore) 2017;96: e7685.

49. DaVee T, Ajani JA, Lee JH. Is endoscopic ultrasound examination necessary in the management of esophageal cancer? World J Gastroenterol 2017;23:751-762.

50. Cooper JS, Guo MD, Herskovic A, et al. Chemoradiotherapy of locally advanced esophageal cancer: Longterm follow-up of a prospective randomized trial (RTOG 85-01). Radiation Therapy Oncology Group. JAMA 1999; 281:1623-1627.

51. Oh D, Noh JM, Nam H, et al. High-dose radiation therapy alone by moderate hypofractionation for patients with thoracic esophageal squamous cell carcinoma. Medicine (Baltimore) 2016;95:e4591.

52. Okawa T, Kita M, Tanaka M, Ikeda M. Results of radiotherapy for inoperable locally advanced esophageal cancer. Int J Radiat Oncol Biol Phys 1989;17:49-54.

53. Sykes AJ, Burt PA, Slevin NJ, et al. Radical radiotherapy for carcinoma of the oesophagus: An effective alternative to surgery. Radiother Oncol 1998;48:15-21.

54. Chen SS, Zhang AQ, Wu T. Progress in traditional chinese medicine in the treatment for esophageal cancer. China Cancer 2013;22:909-913.

55. Fu LX, Huang CG, Lin BM, et al. Progress of quassinoids class of Brucea javanica composition and pharmacological activity research. Chin Pharmacol Bull 2016;32: 1481-1486.

56. Lu GX, Fan JY, Ma RL. The progression of clinical application of Brucea javanica. J Inner Mongolia Med Univ 2012;34:423-427.

57. Yang Q, Zheng LN, Xie YZ, et al. Study on adjoint toxical mechanism of anti-inflammatory effect of different extract from fructus Bruceae. Chin J Pharmacovigilance 2011;8: 333-335.

58. Ding CX, Xuo YR. Research progress on chemical constituents and pharmacology of traditional Chinese medicine. Chin Tradit Patent Med 2006;28:117120.

59. Lou GG, Yao HP, Xie LP. Brucea javanica oil induces apoptosis in T24 bladder cancer cells via upregulation of caspase-3, caspase-9, and inhibition of NF-kappaB and COX-2 expressions. Am J Chin Med 2010;38:613624.

60. Chen M, Chen R, Wang S, et al. Chemical components, pharmacological properties, and nanoparticulate 
delivery systems of Brucea javanica. Int $\mathrm{J}$ Nanomed 2013;8:85-92.

61. Hu Y, Wan XJ, Pan LL, et al. Effects of Brucea javanica oil emulsion on human papilloma virus type 16 infected cells and mechanisms research [in Chinese]. Chin J Integr Tradit West Med 2013;33:1545-1551.

62. Ma QS, Pang YX, Yang Q, et al. Advances in pharmacological activities and anti-tumor mechanisms of Brucea javanica. Guizhou Agric Sci 2015;43:137-1340.

63. Wang J, Huang SW. Antitumor effect of Brucea javanica oil dry milk capsule and its effect on immune function. J Shanxi Coll Tradit Chin Med 2013;14:34-35.

64. Lou LL, Xie W, Zhang P, et al. Effectiveness of traditional Chinese medicine plus chemotherapy in treatment of esophageal cancer: A network meta-analysis. J Lanzhou Univ (Med Sci) 2016;42:55-60.

Address correspondence to: Jiarui $W u, M D, P h D$

Department of Clinical Chinese Pharmacy School of Chinese Materia Medica Beijing University of Chinese Medicine

Beijing 100102

China

E-mail: exogamy@163.com 